\title{
The "lab in your phone" game that taught me four key transferable skills
}

Loriana Vitillo collaborated with sociologists, film-makers and game developers to develop an app that simulates her life as a stem cell researcher.

\section{By Loriana Vitillo}

My phone buzzes and asks me to check on my cells: "they are not looking too happy". I move my finger to the corner of the screen and issue the instruction to feed a cluster of cartoon-blue stem cells. They giggle and smile up at me. I lock my phone. I'm in isolation, at home and far from the lab, due to the global pandemic. But I can still play my life as a scientist on the App game I have co-created with sociologists at Cambridge University.

Dish Life: The Game, was not developed to help with the sudden halt to lab research caused by coronavirus, but to virtually put anyone in the shoes of a scientist. You start by creating your own avatar and then embark on a stem cell career from undergraduate to professor through working in the lab, completing research papers, solving ethical dilemmas, chatting with colleagues and upgrading the office while keeping the demanding stem cells alive. If it feels familiar to some of you, that's because it's supposed to.

I designed a game about my life in the lab because I wanted to find a new way to show the public the realities of being a scientist. Science in general and stem cell research in particular felt like hot topics that needed to be seen past the closed academic doors and engaged with first-hand. The idea of involving people directly with a 'lab in your phone' felt to me to be an exciting challenge. And with the option to customise your own avatar I wanted to contribute to the view that anyone can do science.

\section{How did it happen?}

Dish Life started in the spring of 2016, in my office at the Cambridge Stem Cell Institute. I received an email about a Cambridge University grant competition aimed at science and humanities researchers to collaborate with local filmmakers to showcase their research. They wanted interdisciplinary ideas that could be turned into engaging short films to allow scientists to share their work with the public in an accessible and innovative form. I felt it was the chance I had been waiting for to talk about the human aspect of my research in a creative way.

The next step was to find a collaborator who might be interested in putting together the grant proposal for the film pitch. I found the reproductive sociology research group led by Sarah Franklin, who studies the social aspects and ethics of stem cell research. We discussed an idea for a film about stem cell scientists' emotional relationship with their cells and the first version of Dish Life, a film, was born. Soon after, I met Franklin's student Karen Jent, who was preparing a PhD thesis on the challenges that stem cell scientists face in turning cell cultures in the lab into therapies outside it. We realised that by marrying our disciplines we could shed light on the human aspects of science for a broad audience and we could base it on published sociological research. 
Months later we premiered the Dish Life documentary together with filmmaker Chloe Thomas, who wrote and directed it. We couldn't have done it alone, each of us playing a different and irreplaceable role.

The film then travelled the world at film festivals and, a year later, on the strengths of the response it received, we decided to take it a step further and create a game based on the film. We soon realised we needed a bigger team and funds. Jent's sociologist colleagues Lucy van de Wiel joined the team and Chloe stayed on board as creator in the game's genesis. Funds were raised with grants from the Wellcome Trust and the UK Economic and Social Research Council with the backing of the reproductive sociology research group.

We then called on game developer pitches and accepted one from Pocket Sized Hands, a gaming design company based in Dundee. The game developers visited the Cambridge Stem Cell Institute's lab to hold focus groups with scientists, sociologists and secondary school teachers. For two years we co-designed remotely over the collaboration platform Slack and teleconference, shaping the concept with art designers and coders, incorporating user feedback, always trying to strike the balance between game mechanics and scientific accuracy.

\section{The career benefits of making a science game}

I don't think for a minute that we set out to do this knowing the skills we would acquire along the way. This is what I have learned:

- Communication: The multi-disciplinary nature of the project taught me how to be clear and succinct. I had to communicate across three different fields, making the academic messages meet the demands of the gaming world. The whole experience has also been a learning curve in project management and on being enterprising.

- Intellectual property: We navigated the IP landscape and paired with Cambridge Enterprise, the university's research commercialisation arm, to stipulate the licencing aspects for updating the app and free to download. This was a completely new process for everyone in the context of games created by academics.

- Media coverage: Close to the launch, I entered a new world of writing university press releases and handling media relations. I even had a crash course in TV broadcasting when BBC News decided to cover Dish Life.

- Impact: The amount of people we went on to reach with the game overshadowed any public engagement event I was ever involved in; we reached thousands of people in the space of weeks. We had professors reliving their heydays with their avatars, A-level students endorsing it, and even had a blogger writing a step-by-step guide on how to become a professor in the game.

My advice to researchers interested in increasing their public engagement impact is to really look around the university and beyond and start new collaborations. A surprising thing I 
learned is that people are overwhelmingly interested in our working lives, they want to see how we do science. I didn't know I was going to end up making a game, but I am glad I took that initial leap of faith.

Now I can go back to play being a scientist until they let us back in the building again.

Loriana Vitillo is a postdoctoral stem cell scientist at University College London, UK. You can find her science communication @LorianaVitillo

Careers

Lab life

Communication

Enterprise: Game on

https://www.nature.com/articles/nj7663-369a

Communicating science at a music festival - with 135,000 attendees

https://www.nature.com/articles/d41586-019-02423-9

Social media for scientists

https://www.nature.com/collections/gbhiidjaha/

Collection: Technology

https://www.nature.com/collections/fxvqrpnlcq 